\title{
Synthesis and Evaluation of Gyps vulture Multidrug Resistant Protein 4 (MRP4/ABCC4) Specific Multiple Antigenic Peptide (MAP) for its Immunoreactivity
}

\author{
Mashidur Rana ${ }^{1}$, Mohini Saini ${ }^{1 *}$, Sasmita Barik ${ }^{1}$, $\operatorname{Ram~Bachan}^{1}$, Deepika Bisht ${ }^{2}$, Supriya \\ Bhattacharya $^{2}$, P. Kirthika ${ }^{3}$, Praveen Singh ${ }^{3}$, Satish Kumar ${ }^{3}$ and Praveen K. Gupta ${ }^{2}$ \\ ${ }^{I}$ Division of Biochemistry, ${ }^{2}$ Division of Veterinary Biotechnology, \\ ${ }^{3}$ Central Instrumentation and Bioengineering Facility, ICAR-Indian Veterinary Research \\ Institute, Izatnagar, Bareilly, U.P-243122, India \\ *Corresponding author
}

\section{A B S T R A C T}

\section{Keywords}

Gyps himalayensis,

Vulture, MRP4

(Multi Drug

Receptor Protein 4),

$\mathrm{ABC}$ (ATP binding

cassette)

superfamily, MAP

(Multi Antigenic

Peptide), SPPS

(Solid Phase

Peptide Synthesis)

Article Info

Accepted:

12 November 2018

Available Online:

10 December 2018
Efforts are in progress to conserve critically endangered Gyps spp. vultures by identifying and removing the vulture-unsafe drugs from the food chain. Several drugs namely diclofenac, aceclofenac, ketoprofen and nimesulide are found to cause hyperuricemia and fatal nephrotoxicity in Gyps vultures. Research on development of an in vitro model for screening drugs in practice and the new molecules for their hyperuricemic potential can facilitate the conservation efforts. Multi drug resistant protein 4 (MRP4/ABCC4) is an efflux transporter on the luminal side of proximal renal tubular membrane that plays key role in urate as well as drug transport. In the present study, we report development and use of Gyps himalayensis MRP4 specific multiple antigenic peptide (MAP). Sequences of linear peptide and $\mathrm{N}$ terminal immunodominant region of Gyps himalayensis MRP4 was predicited in silico. Tetrameric MAP was synthesized in solid phase synthesis (SPPS) using Wang resin and employed for immunization of rabbit for obtaining polyclonal serum. $\mathrm{N}$ terminal region (1-737 amino acids) of vulture MRP4 predicted to contain immunodominant epitopes was expressed in E. coli BL21 cells and purified in Ni-NTA affinity chromatography. The $\sim 24 \mathrm{kDa}$ purified protein could be detected in immunoblots using anti-MAP serum indicating its potential in detection of MRP4 expression. This hyperimmune serum can be exploited for its use in detection of MRP4 expression in avian renal tubular cells or MRP4 expressing cells before their use for screening drugs for their role in urate transport.

\section{Introduction}

In South Asian subcontinent, three resident Gyps species vultures, Gyps indicus, Gyps bengalensis and Gyps tenuirostris are 'Critically endangered' and migratory species Gyps himalyensis moved from 'Least concern' to 'Near threatened' category (https://www. iucnredlist.org/search?taxonomies $=22675030$ $\&$ searchType $=$ species $)($ Prakash et al., 2017). Gyps vultures got exposed to the non-steroidal anti-inflammatory drug diclofenac through food chain and experienced fatal nephrotoxicity that proved to be the major 
cause of catastrophic decline in their population (Cuthbert et al., 2014, 2015). Since the detection diclofenac as the culprit drug in dead birds (Oaks et al., 2004; Green et al., 2004) as well as experimentally treated vultures (Swan et al., 2006a and b), several other drugs like ketoprofen (Naidoo et al., 2017), fluxicin (Zorrilla et al., 2015), aceclofenac (Galligan et al., 2016), nimesulide (Cuthbert et al., 2015) are reported to produce hyperuricemia and toxicity akin to that of diclofenac in vultures. Meloxicam being the only proven vulture-safe molecule (Swan et al., 2006a;Swarup et al., 2007) and increasing evidence of many molecules being detected to be nephrotoxic in Gyps vultures emphasizes the need for toxicity testing of veterinary drugs in practice and the new molecules in order to ensure some vulture-safe drugs. However, testing all molecules in vivo is not practical due to limited number of these critically endangered species (Prakash et al., 2017). Furthermore, Gyps vultures are highly sensitive to drugs like diclofenac as compared to other avian species like chicken, crow and turkey vulture (Rattner et al., 2008; Naidoo et al., 2011); the possibility of screening drugs in surrogate species is also ruled out.

Diclofenac toxicity in Gyps vulture has been shown to be associated with decreased uric acid excretion (Naidoo and Swan, 2009). Urate transport across proximal renal tubular cells is considered to be unidirectional in birds that results from coordinated efforts of organic anion transporter 1/3 (OAT1/OAT3) on basolateral side and multidrug resistant protein 4 (MRP4/ABCC4) on the luminal side (Dudas et al., 2005; van Aubel et al., 2005; Batallie et al., 2008).

The core structure of MRP4, a typical ABC transporter comprises of two membranespanning domains, each consisting of six trans-membrane helices with two cytosolic ATP-binding domains (Borst et al., 2007).
Cell-culture based screening can provide an alternative approach for testing the molecules for nephrotoxic potential. HEK293 and SF9 cells expressing human MRP4 for studying the effect of drugs on urate transport have been employed (van Aubel et al., 2005; El Sheikh et al., 2008). Likewise, use of cells expressing vulture MRP4 for screening of drugs for their urate transport inhibitory potential can be explored, for which means to characterize MRP4 expression needs to be established. In an earlier study (Batallie et al., 2008), MRP4 protein in chicken proximal renal tubular cells was detected by using a custom affinitypurified polyclonal antibody designed against peptide C-N-G-Q-L-A-T-D-S-S-L-D-P-S-S localized in a region near $\mathrm{C}$-terminal end of the chicken MRP4 sequence. We have observed that $A B C C 4 / M R P 4$ is transcribed as two transcript variants in chicken and vulture and both of them produce functional protein (Barik, 2016). These variants are likely to produce proteins differing in 19 amino acids at C-terminal end, thus the antibody serving as a tool for MRP4 detection should be able to identify both the transcript variants. Multiple antigenic peptides (MAPs) provide potent antigen to produce mono-specific serum with high titre (Dyson et al., 1988; Tam, 1988). Here, we report designing, synthesis and evaluation of $\mathrm{N}$-terminal specific multiple antigenic peptide specific polyclonal serum for immune-detection of vulture MRP4.

\section{Materials and Methods}

In silico analysis of the $\mathrm{N}$-terminal region of MRP4 of Gyps himalayensis to determine the immunodominant and signal peptide containing region

N-terminal region (1-737 amino acids) of predicted MRP4 of Gyps himalayensis (Accession KX168697) was analysed using online tools from IEDB Analysis Resource 
(http://tools.iedb.org/bcell/) for linear epitope prediction (Larsen et al., 2006; Jespersen et al., 2017) and hydrophilicity (Parkeret al., 1986). The topology of the protein was checked by using online platform from Stockholm Bioinformatics Centre (http://phobius.sbc.su.se/index.html) using the phobius algorithm (Kället al., 2007).

Synthesis and purification of multiple antigenic peptide (MAP)

\section{Preparation of Fmoc-Cys-Wang}

$100 \mathrm{mg}$ Wang resin was dissolved in $3 \mathrm{ml}$ of Dimethylformamide (DMF) and poured into a clean Merrifield flask. In a separate $5 \mathrm{ml}$ tube, $234.20 \mathrm{mg}$ Fmoc -cysteine was dissolved in 3 $\mathrm{ml}$ DMF and $34 \mu \mathrm{l}$ of $\mathrm{N} \quad, \mathrm{N}^{\prime}$-Diisopropyl carbodiimide (DIPC) was added to the solution and incubated at $4^{\circ} \mathrm{C}$ for $20 \mathrm{~min}$. After incubation, the entire solution containing cysteine was poured into the Merrifield flask after draining out the excess DMF and then 0.1 equivalent of catalytic p-dimethyl aminopyridine (DMAP) was added to it. The flask was properly sealed and kept in constant shaking (200 RPM) at $4^{\circ} \mathrm{C}$ for overnight. The product so obtained is Fmoc-Cys-Wang.

\section{Coupling of Di-Fmoc-Lys to $\mathrm{NH}_{2}$-Cys- Wang}

The excess DMF was drained out and the flask was washed twice with DMF, di-chloro methane (DCM) and DMF, respectively. Then capping of free functional groups on Wang resin was done by incubating the resin in $2 \mathrm{ml}$ acetylation mixture [DMF: Acetic anhydride: DIEA (193: 6: $1, \mathrm{v} / \mathrm{v})]$ at $4^{\circ} \mathrm{C}$ and constant shaking $(200 \mathrm{rpm})$ for $20 \mathrm{~min}$. After incubation, excess solution was drained out and the flask was washed with DMF and DCM as above. Then, $4 \mathrm{ml}$ of $20 \%$ piperidine in $\mathrm{DMF}(\mathrm{V} / \mathrm{V})$ was added to the flask and again incubated at $4{ }^{\circ} \mathrm{C}$ and constant shaking (200 rpm) for $20 \mathrm{~min}$. The flask washing with
DMF and DCM was performed as mentioned above. In an Eppendorf tube, $118.14 \mathrm{mg}$ of Di-Fmoc-Lys, 27.06 mg of 1Hydroxybenzotriazole (HOBt) and $72.06 \mathrm{mg}$ of 2-(1H-Benzotriazole-1-yl)-oxo-1,2,3,3tetramethyluronium hexa- fluorophosphate (HBTU) was weighed and dissolved in DMF and stored at $4^{\circ} \mathrm{C}$ for $20 \mathrm{~min}$. Then $150 \mu \mathrm{l}$ of N,N-Diisopropyl ethylamine (DIEA) was added to the tube. The content of the entire tube was now emptied into the Merrifield flask and incubated for $2 \mathrm{~h}$ at $4^{\circ} \mathrm{C}$ for coupling. Thereafter, again the acetylation mixture was prepared and added to the flask after emptying it and kept for constant shaking $(200 \mathrm{rpm})$ at $4^{\circ} \mathrm{C}$ for $30 \mathrm{~min}$. Thereafter, the flask was washed thrice with DMF and then 4 $\mathrm{ml}$ of $20 \%$ piperidine in DMF was added to the flask and incubated at $4^{\circ} \mathrm{C}$ for $20 \mathrm{~min}$ in constant shaking. The resultant product in this step is Di-Fmoc-Lys bound to $\mathrm{NH}_{2}$-CysWang.

\section{Preparation of branched Lysine four arm of the MAP core}

In the constructed MAP, branching was achieved to form four arm structure using diFmoc-Lys-OH to provide lysine core over which chosen peptide sequence was synthesized using $\mathrm{Fmoc}(\mathrm{N \alpha}-9$ Fluorenylmethyloxycarbonyl) solid-phase peptide synthesis (Fig. 2).

The flask was washed twice with DMF, dichloro methane (DCM) and DMF, respectively. In an Eppendorf tube $236.28 \mathrm{mg}$ of di-Fmoc-Lys, $54.12 \mathrm{mg}$ of HOBt and $147.29 \mathrm{mg}$ of HBTU was weighed and dissolved in DMF and stored at $4^{\circ} \mathrm{C}$ for 20 min. Further steps were carried out as described above to yield the formation of four dendritic arms of lysine bound to di-FmocLys- $\mathrm{NH}_{2}$-Cys-Wang.

\section{Coupling of MAP}

Each successive Fmoc-amino acid to be used 
in peptide synthesis was activated by $\mathrm{HOBt}$ and HBTU and coupled in the presence of DIEA one by one until the desired length of the multimeric peptide was obtained.

\section{Freeing MAP from resin}

Final chemical deprotection and cleavage was done by treating resin bound peptides with the cleavage mixture [Trifluoroaceticacid: $\mathrm{m}$ cresol: Thioanisol: Ethanedithiol: Water (82.5: 5: 5: 5: 2.5, v/v)]. Lastly, cleaved MAP was precipitated with chilled (dry) diethyl ether, vacuum dried and stored under dry conditions until further used for immunisation.

\section{Generation of hyperimmune serum in rabbit against MAP}

After obtaining due permission from Institute Animal Ethics Committee, one four months old New Zealand white female rabbit weighing $3.0 \mathrm{~kg}$ was procured from Laboratory Animal Resources, ICAR-Indian Veterinary Research Institute, Bareilly, Uttar Pradesh, India. All the guidelines of CPCSEA were strictly followed to minimize stress and discomfort and the animal was monitored daily for any disease condition. Preimmunization serum was collected aseptically from the marginal ear vein of rabbit. Emulsion consisting of an equal volume of MAP (250 $\mu \mathrm{g}$ of antigen) and Freund's incomplete adjuvant (FIA) (Santa Cruz) was formulated. The rabbit was immunized with the emulsion prepared parenterally by intramuscular route at 2 sites $(0.5 \mathrm{ml} / \mathrm{site})$.

Subsequent boosters were administered at 7 th, 14th and 28th days post-first immunization using an emulsion made of an equal volume of MAP (100 $\mu \mathrm{g}$ of antigen) and FIA. Finally, 10 $\mathrm{ml}$ of blood was collected from ear vein on the 35 th day post-first immunisation. The serum after extraction from blood was stored at $20^{\circ} \mathrm{C}$ till further use.
Construction of recombinant plasmid (pRSET-rNvMRP4) containing coding region for short $\mathrm{N}$-terminal stretch of MRP4

Based on in silico analysis, the stretch of amino acids from 533 to 698 residues of complete vulture MRP4 (Accession KX168697) was selected as the antigenic region (rNvMRP4) to be expressed in frame with 6X-Histidine tag of the vector backbone. Gene specific primer pair including Forward 5'-AAAGGATCCGGAGCTACACTGAGTG$3^{\prime}$ and Reverse 5'-GAAGAA TTCTTTT CCCTCAGAACGACT-3' was designed to amplify respective 512 bp coding region using pCDNAV5/His-MRP4 (Barik, 2016) as template and synthesized at Eurofins, Bangalore, India. Forward and reverse primer incorporated Bam HI and Eco RI restriction sites, respectively to facilitate directional cloning in prokaryotic expression vector pRSET-A (Invitrogen).

PCR reaction consisted of both forward and reverse primers $(50 \mathrm{pmol}) 2.5 \mu \mathrm{l}$ each, 1:10 diluted pCDNAV5/His-MRP4 (Barik, 2016) as template $0.5 \mu \mathrm{l}$; and Phusion high fidelity master mix with GC buffer (New England Biolabs) $25 \mu \mathrm{l}$ and final volume made upto 50 $\mu \mathrm{l}$ using nuclease free water. PCR reaction conditions were as follows: initial denaturation $98^{\circ} \mathrm{C}$ for $30 \mathrm{sec}$, followed by 30 repeated cycles of $98^{\circ} \mathrm{C}$ for $7 \mathrm{sec}, 58^{\circ} \mathrm{C}$ for 30 sec, $72^{\circ} \mathrm{C}$ for $30 \mathrm{sec}$ and final extension at $72^{\circ} \mathrm{C}$ for $10 \mathrm{~min}$. The $512 \mathrm{bp}$ amplicon was purified using PCR clean up kit (Qiagen) and double digested with Bam HI (New England Biolabs) and Eco RI (MBI Fermentas). The ligation mixture containing double digested PCR product $(3 \mu \mathrm{l})$, pRSET A vector $(1 \mu \mathrm{l})$, 10X ligation buffer $1 \mu \mathrm{l}$ and T4 DNA ligase 1 $\mu \mathrm{l}$ (New England Biolabs) and the volume adjusted to $10 \mu \mathrm{l}$ using nuclease free water was incubated at $4{ }^{\circ} \mathrm{C}$ overnight. The ligation mixture was transformed to E. coli BL21 (Novagen) competent cells using the TSS 
method (Chung et al., 1989) and grown at $37^{\circ} \mathrm{C}$ overnight on LB agar plates containing chloramphenicol $(34 \mu \mathrm{g} / \mathrm{ml})$, ampicillin (100 $\mu \mathrm{g} / \mathrm{ml})$ and $1 \%$ glucose.

\section{Expression, purification and characterization of recombinant rNvMRP4}

These transformed cells were grown in LB broth supplemented with $1 \%$ glucose and antibiotics $(100 \mu \mathrm{g} / \mathrm{ml}$ ampicillin and $35 \mu \mathrm{g} / \mathrm{ml}$ chloramphenicol) on shaker-cum-incubator at $37^{\circ} \mathrm{C}$ and $180 \mathrm{rpm}$. When the optical density of the culture at $600 \mathrm{~nm}$ reached 0.6 , isopropyl beta-D-thiogalactoside (Invitrogen) was added at to a final concentration of $1 \mathrm{mM}$ followed by incubation at $37^{\circ} \mathrm{C}$ for four hours at 180 $\mathrm{rpm}$ to induce protein expression. The cells were pelleted and lysed in lysis buffer $(6 \mathrm{M}$ Guanidium Hydrochloride, 100mM NaH${ }_{2} \mathrm{PO}_{4}$, $10 \mathrm{mM}$ Tris-Chloride, $\mathrm{pH} 8.0$ ) by mild agitation for 1 hour at room temperature at 80 rpm. The lysate was centrifuged at $10000 \mathrm{rpm}$ for $30 \mathrm{~min}$ at $4{ }^{\circ} \mathrm{C}$ and the supernatant so obtained was incubated with Ni-NTA agarose (Qiagen) for 1 hour at room temperature with mild shaking at $80 \mathrm{rpm}$. After incubation, the entire slurry was loaded into the polypropylene column. The flow through was collected and the column was washed two times with wash buffer (8M Urea, $100 \mathrm{mM}$ $\mathrm{NaH}_{2} \mathrm{PO}_{4}, 10 \mathrm{mM}$ Tris-Chloride, $\mathrm{pH}$ 6.3). The bound protein was then eluted by two buffers, one with pH 5.9 (8M Urea, $100 \mathrm{mMNaH}_{2} \mathrm{PO}_{4}$, $10 \mathrm{mM}$ Tris-Chloride) and then with $\mathrm{pH} 4.5$ (8M Urea, $100 \mathrm{mM} \mathrm{NaH} \mathrm{PO}_{4}, 10 \mathrm{mM}$ TrisChloride). All elutes, flow through and washes were collected and analysed in $15 \%$ Sodium Dodecyl Sulphate-Polyacrylamide Gel Electrophoresis (SDS-PAGE). The concentration of the expressed protein was determined by densitometry against known BSA standards as described by Pecora et al., (2009). The identity of the recombinant protein (rNvMRP4) was confirmed by mass spectrometry. Expressed protein visualized as $\sim 24 \mathrm{kDa}$ band in SDS-PAGE was sliced. The protein samples were trypsin digested and peptides extracted according to standard techniques. Peptides were analysed by a MALDI-TOF mass spectrometer at Sandor Life Sciences, Hyderabad, India. Spectra were analysed to identify the protein of interest using Mascot sequence matching software (Matrix Science).

\section{Evaluation of MAP specific hyperimmune serum}

The polyclonal antiserum against MAP raised in rabbit was tested for reactivity with recombinant MRP4 in dot blot assay and then confirmed in Western blot using semi-dry blot system (Towbin et al., 1979). Briefly, recombinant rNvMRP4was subjected to $15 \%$ SDS-PAGE and protein bands were transferred to nitrocellulose membrane (Bio$\mathrm{Rad})$ using constant current $\left(0.8 \mathrm{~mA} / \mathrm{cm}^{2}\right.$ of the gel) for $90 \mathrm{~min}$. The membrane was blocked in 3\% BSA in phosphate buffer saline (PBS) at $37^{\circ} \mathrm{C}$ for 1 hour and then incubated with rabbit antiserum raised against vulture MRP4 specific MAP diluted in $0.8 \%$ PBSTween (1:500) for 1 hour at $37^{\circ} \mathrm{C}$. After incubation, the membrane was washed and treated with anti-rabbit IgG HRPO conjugate (1:1000) for 1 hour and then the blot was developed with 3,3'-Diaminobenzidine (DAB) as substrate.

\section{Results and Discussion}

Present study reports the development of MAP and expression of partial recombinant MRP4 of Himalayan griffon vulture and also the evaluation of their use to detect the expression in immunoblots. The solid phase peptide synthesis discovered by Merrifield (1963) had unveiled new horizons for widespread applications of synthetic peptides as reagents and biologicals in chemical, biological and biomedical investigations. The short comings of some short peptides to elicit immune response due to their small sizes was soon 
overcome by preparing copies of the epitopic peptide over lysine core matrix referred to as multiple antigenic peptide (Tam 1988). The 13 amino acids (646 to 658) long stretch (T-P-NL-K-S-S-R-S-R-T-F-S) chosen for MAP construction. The tetrameric MAP was constructed on Wang resin by solid phase peptide synthesis (Fig. 2). The ultimate yield of MAP was $54.9 \mathrm{mg}$ after final cleavage from the resin. This stretch was likely to serve as good B cell linear epitope eliciting better immune response that could detect recombinant N-terminal partial MRP4 as antigen.

Earlier, we characterized the complete coding sequence of vulture MRP4/ABCC4 (KX168697) and also identified its two transcript variants of $4050 \mathrm{bp}$ and $3993 \mathrm{bp}$ mRNA sequences coding for polypeptides of 1349 and 1330 amino acids, respectively that differed in 19 amino acids at C-terminal end (Barik, 2016). The MRP4 sequence reported by Bataillie et al., (2008) to be responsible for urate transport in Gallus gallus (Accession NM_001030819.1) lacked the stretch of 19 amino acids. The N-terminal amino acids 1737 are translated in all transcript variants of vulture $M R P 4 / A B C C 4$. Based upon in silico analysis, the stretch of the amino acids selected from 533 to 698 was predicted to be fairly immune-dominant, hydrophobic and lying in the cytoplasm not within the transmembrane region (Fig. 1a, b and c).

Signal peptide predictions in silico also suggested that this selected region does not contain any cleavage site (Fig. 1c) indicating thereby that no portion will be lost as signal sequence during localization of the protein after expression. Thus, the stretch from 533 to 698 amino acids was expressed as recombinant N-terminal partial MRP4 (rNvMRP4). For amplification of 512 bp partial sequence from pCDNAV5/His-MRP4 using expression primers, $58^{\circ} \mathrm{C}$ was found to be the optimum annealing temperature. The PCR product was cloned in prokaryotic expression vector and the resulting recombinant plasmid pRSET-rNvMRP4 was characterized in PCR and restriction analysis (Fig. 3a and b). Visualization of 512 bp amplicon in PCR (Fig. 3a) and linearised 3412 bp recombinant plasmid in RE digestion (Fig. 3b) confirmed the presence of insert. Presence of Bam HI site at the start of the insert and that of $B g l$ II site in the vector backbone, yielded a linear product of equal length upon digestion confirming the recombinant construct.

The SDS-PAGE analysis of the expressed rNvMRP4 revealed that $\sim 24 \mathrm{kDa}$ protein was eluted in $\mathrm{pH} 4.5$ buffer (Fig. 4a). Upon MALDI-TOF analysis, the protein was found to align with Gallus gallus Multi Drug Receptor proteins (Fig. 4b). Besides MRP4, the peptides also matched with MRP1, MRP2 and P-Glycoprotein due to conserved nature of these transporters in their $\mathrm{N}$-terminal regions (https://www.ncbi.nlm.nih.gov/Structure/cdd/c ddsrv.cgi?uid=330224).

Densitometric analysis against known dilutions of BSA standards resolved in SDSPAGE gels was preferred to quantify the recombinant protein as some minor bacterial proteins also get eluted in Ni-NTA column during purification.

The concentration of purified rNvMRP4was found to be $1 \mu \mathrm{g} / \mu \mathrm{l}$. The rabbit hyperimmune serum raised against this purified rNvMRP4 was evaluated in dot blot assay. Absence of reactivity in the pre-immune serum suggested the specific reactivity of the hyperimmune serum (Fig. 5a). Western blot (Fig. 5b) revealed that the hyperimmune serum was able to detect the expressed $\sim 24 \mathrm{kDa} N$ terminal epitopic region of vulture MRP4/ABCC4. 
Fig.1 In silico analysis of N-terminal region (1-737 amino acids) of predicted Multi Drug Resistant Protein 4 (MRP4) of Gyps himalayensis (Accession KX168697). (a) Linear epitope prediction. (b) Hydrophilicity plot. (c) Topology check and signal peptide cleavage site prediction

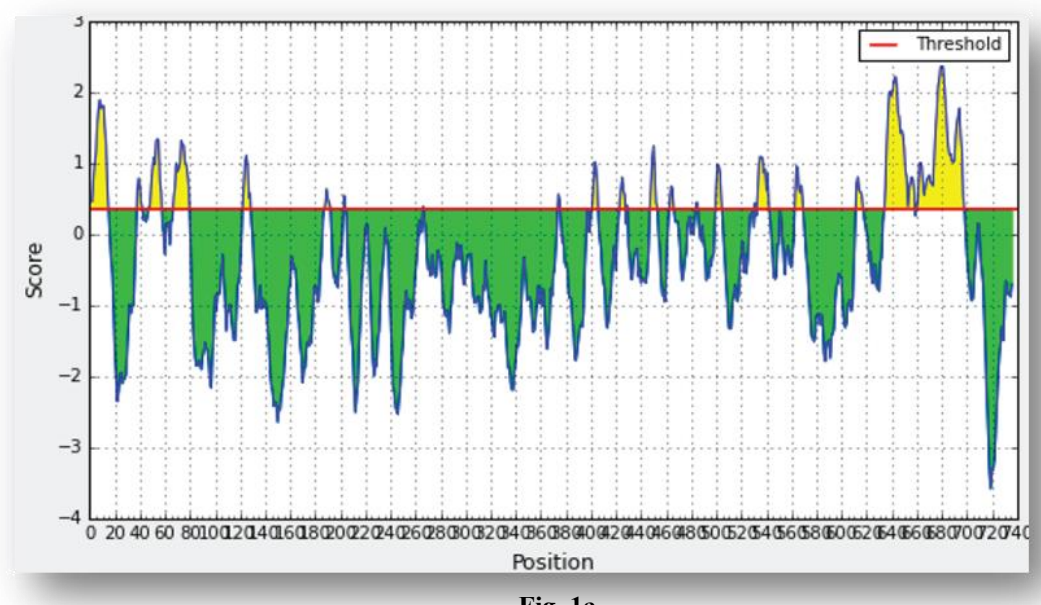

Fig. 1a

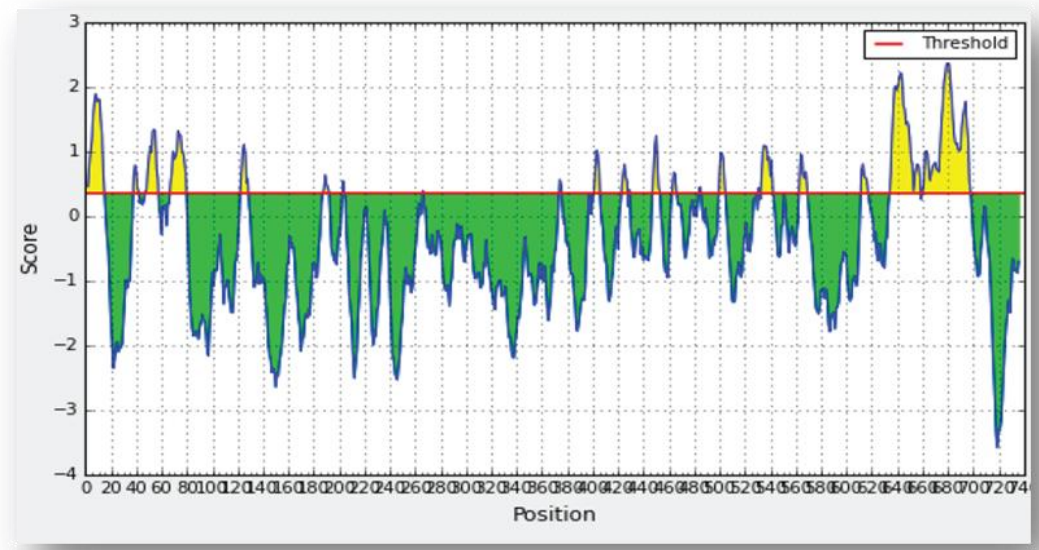

Fig. 1b

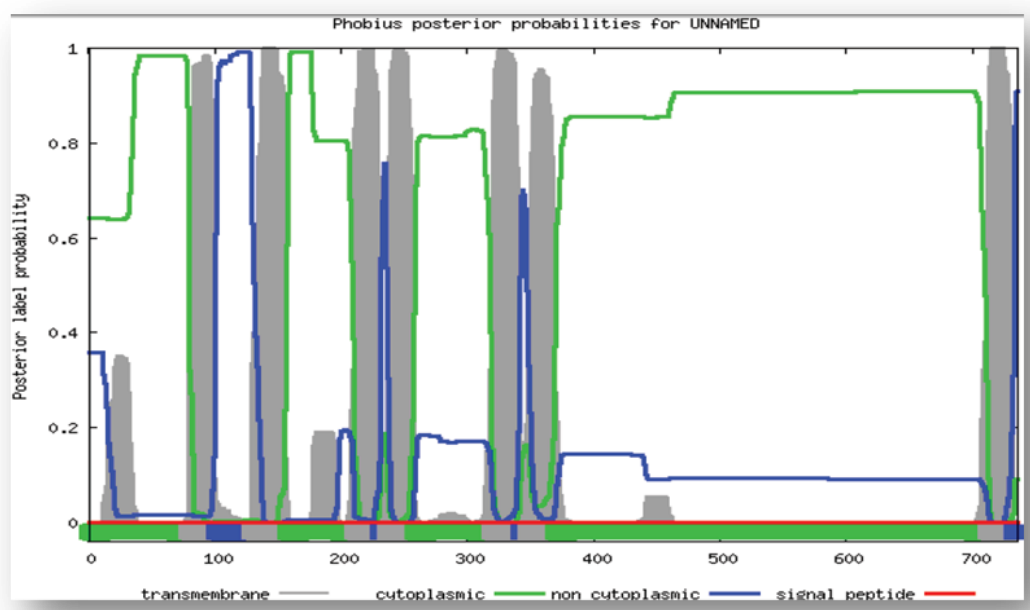

Fig. 1c 
Fig.2 Schematic representation of the synthesized Multi Antigenic Peptide. Amino acids in box represent the MAP core bound to Wang resin shown in circle. The 13 amino acid peptide arms are marked in red [646-658 amino acids of N-terminal region of Multi Drug Resistant Protein 4 (MRP4) of Gyps himalayensis (Accession KX168697)]

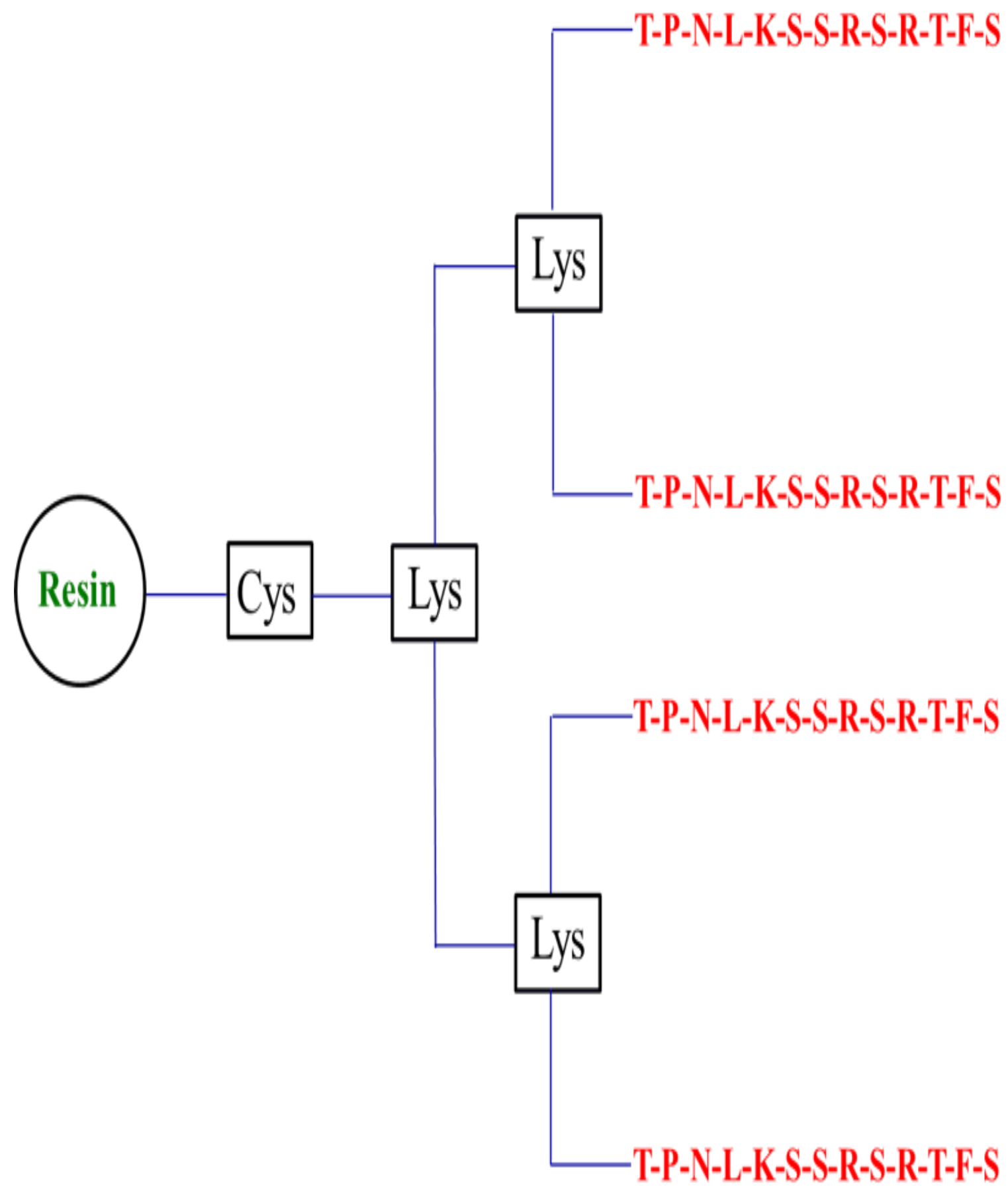


Fig.3 Characterization of recombinant plasmid (pRSET-rNvMRP4) containing partial coding region pertaining to N-terminal region of Multi Drug Resistant Protein 4 (MRP4) of Gyps himalayensis. (a) 1\% agarose gel (1X TAE) electrophoresis of $500 \mathrm{bp}$ amplicon in PCR using pRSET-rNvMRP4 as template [M: 100 bp plus ladder; Lane 1: pRSET-rNvMRP4]. (b) 1\% agarose gel (1X TAE) electrophoresis of pRSET-rNvMRP4 digested with Bam HI (Lane 2) and Bgl II (Lane 3) against uncut pRSET-rNvMRP4 (Lane 1) [M: 1 kb plus ladder]

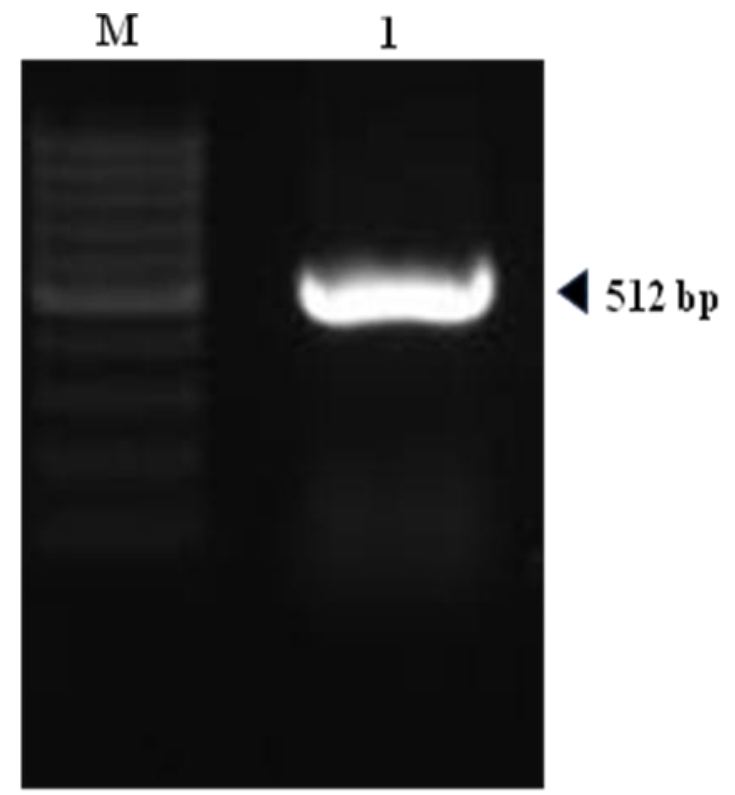

Fig.3a

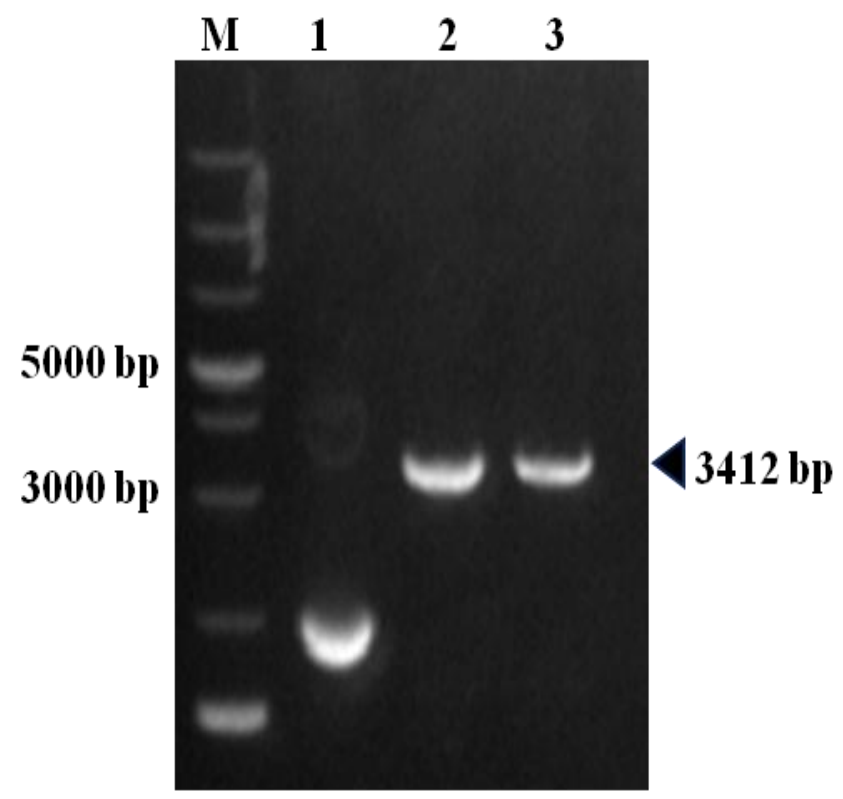

Fig. 3b 
Fig.4 Purification and characterization of recombinant protein containing N-terminal region of Multi Drug Resistant Protein 4 (MRP4) of Gyps himalayensis (rNvMRP4) (a) 15\% SDS-PAGE analysis of the expressed recombinant protein (rNvMRP4) in buffer with pH 4.5 ( 24 kDa) using

Ni-NTA affinity column chromatography [M: Protein molecular weight marker, L 1-9:

Successive elutes in $\mathrm{pH} 4.5$ buffer]. (b) MALDI-TOF analysis of the recombinant protein (rNvMRP4)

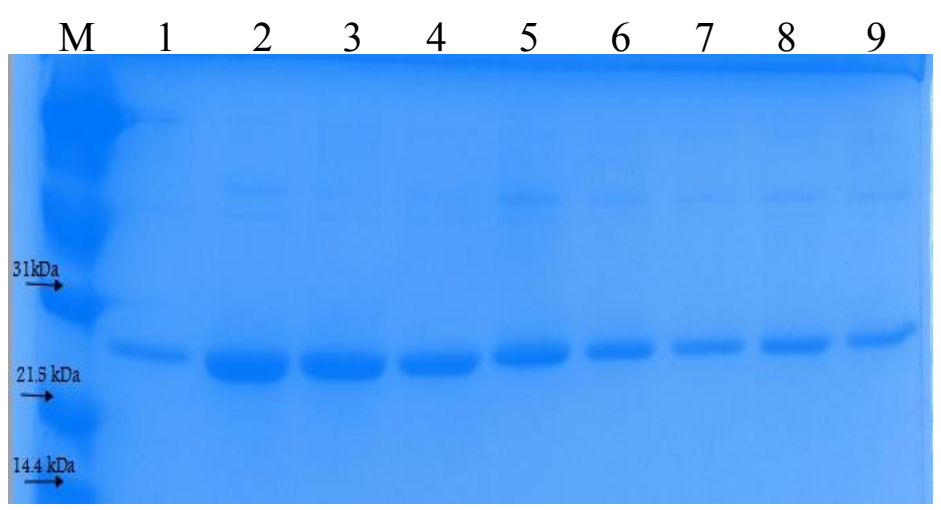

Fig. 4a

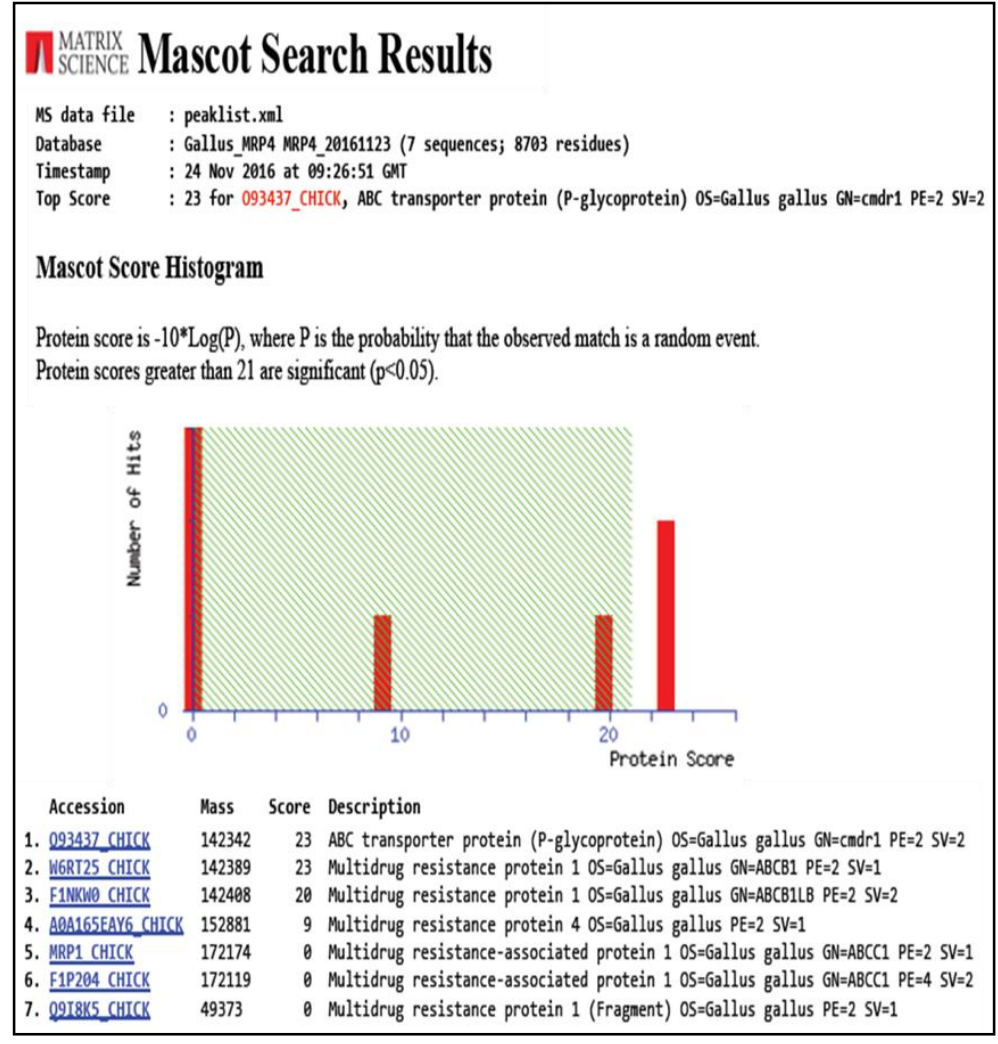

Fig. 4b 
Fig.5 Immunoreactivity of the MAP specific hyperimmune serum with $\mathrm{N}$-terminal region of Multi Drug Resistant Protein 4 (MRP4) of Gyps himalayensis (rNvMRP4). (a) Dot-blot assay to check the reactivity of the MAP specific hyperimmune serum [Pre: pre-immune serum; Post: pos-immune serum]. (b) Western blot indicating the specific reactivity of MAP specific hyperimmune serum with rNvMRP4 [M: protein marker; L: rNvMRP4]

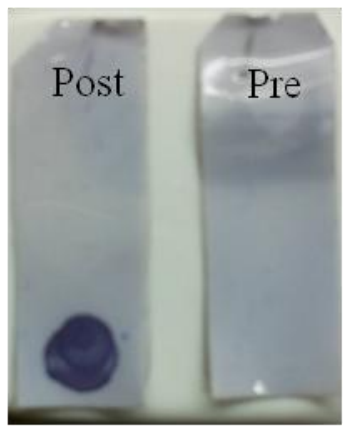

Fig. 5a

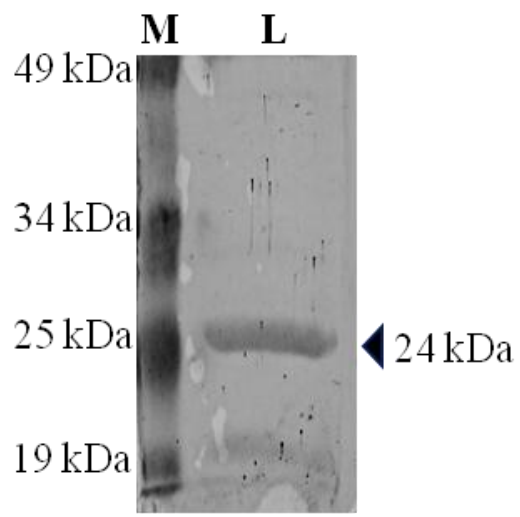

Fig. 5b

Thus, the MAP derived hyperimmune serum was found to be reactive and was successfully used to detect the recombinant linear epitope. Thus, the serum possesses all the required potential to screen for expression of MRP4 in in vitro models, though the detection of expression in avian renal tubular cells or MRP4 expressing cells have to be characterized in further studies.

Earlier, Batallie et al., (2008) detected MRP4 protein in chicken proximal renal tubular cells by using a custom affinity-purified polyclonal antibody designed against $C$-terminal specific peptide C-N-G-Q-L-A-T-D-S-S-L-D-P-S-S. Except for Cys at $\mathrm{N}$ terminal region, this sequence is likely to be present in both the translation products of transcript variants that may aid in detection of MRP4 expression. Short hairpin RNA interference (shRNAi) studies in primary monolayer of chicken proximal tubular cells proved that MRP4 is used for urate secretion in birds (Battaile et al., 2008). 
Being specific to $\mathrm{N}$-terminal region, MAP developed in this study can invariably detect products translated from all known transcript variants of vulture $M R P 4$. Nevertheless, $\mathrm{ABC}$ group of transporters have a conserved $\mathrm{N}$ terminal domain hence the MAP derived hyperimmune serum can also be used for detection of expression of other transporters of $\mathrm{ABC}$ superfamily. Besides this, the in silico analysis reported here can further be used to design alternative MAPs or recombinant proteins for detection of the members this family of transporters.

In addition to urate, MRP4 has the ability to transport, a range of endogenous molecules as well as exogenous drugs (Kanamitsu et al., 2017; Murray et al., 2017). Characterization of MRP4 expression in renal cells/ expressing cell lines can help develop an in vitro model for studying transport of endogenous as well as exogenous molecules

\section{Acknowledgement}

The authors are grateful to the Director, Joint Director (Academics), and Joint Director (Research), Indian Veterinary Research Institute, Izatnagar for providing necessary facilities to conduct the present study. Financial support to MR in terms of ICMRJRF is deeply acknowledged.

\section{References}

Barik, S. 2016. Characterization of multi drug resistant protein 4 (MRP4) in Gyps himalayensis and Gallus domesticus for its role in drug induced nephrotoxicity. Ph.D. Thesis, ICAR- Indian Veterinary Research Institute, Bareilly, India.

Bataille, A. and Goldmeyer, J. 2008. Avian renal proximal tubule epithelium urate secretion is mediated by Mrp4. Am. J.

Borst, P. et al., 2007. Multidrug resistanceassociated proteins 3, 4, and 5. Pflügers Arch. - Eur. J. Physiol.453: 661-673.
Chung CT, Niemela SL, Miller RH. 1989. One step preparation of competent Escherichia coli transformation and storage of bacterial cells in the same solution. Proc Nat Acad Sci USA.86:2172-2175.

Cuthbert, R. J. et al., 2014. Avian scavengers and the threat from veterinary pharmaceuticals. Philos. Trans. R. Soc. Lond. B. Biol. Sci.369: 2013057420130574.

Cuthbert, R. J.et al., 2015. Continuing mortality of vultures in India associated with illegal veterinary use of diclofenac and a potential threat from nimesulide. Oryx 50: 104-112.

Dudas, P. L. et al., 2005. Transepithelial urate transport by avian renal proximal tubule epithelium in primary culture. 4305-4315.

Dyson H.J et al., 1988. The physical basis for induction of protein-reactive antipeptide antibodies. Annu Rev Biophys Biophys Chem.17:305-324.

El-Sheikh, A. A. K. et al., 2008. Effect of hypouricaemic and hyperuricaemic drugs on the renal urate efflux transporter, multidrug resistance protein 4. Br. J. Pharmacol.155: 1066-1075.

Galligan, T. H. et al., 2016. Metabolism of aceclofenac in cattle to vulture-killing diclofenac. Conserv. Biol.30: 1122-1127.

Green, R. E. et al., 2004. Diclofenac poisoning as a cause of vulture population declines across the Indian subcontinent. J. Appl. Ecol.41: 793-800.

Jespersen, M. C. et al., 2017. BepiPred-2.0: improving sequence-based B-cell epitope prediction using conformational epitopes. Nucleic Acids Res.45: W24-W29.

Käll, L. et al., 2007. Advantages of combined transmembrane topology and signal peptide prediction--the Phobius web server. Nucleic Acids Res.35: W429-432.

Kanamitsu, K. et al., 2017. Investigation of the Importance of Multidrug ResistanceAssociated Protein 4 (Mrp4/ Abcc4) in the Active Efflux of Anionic Drugs Across the Blood-Brain Barrier. Journal of Pharmaceutical Sciences 106(9): 25662575.

Larsen, J. et al., 2006. Improved method for 
predicting linear B-cell epitopes. Immunome Res.2:2.

Merrifield, R. B. 1963. Solid Phase Peptide Synthesis. I. The Synthesis of a Tetrapeptide. J. Am. Chem. Soc. 85(14): 2149-2154.

Murray, J. et al., 2017. Suppression of the ATPBinding Cassette Transporter ABCC4 Impairs Neuroblastoma Tumour Growth and Sensitises to Irinotecan in Vivo. European Journal of Cancer 83:132-141.

Naidoo, V. and Swan, G. E. 2009. Diclofenac toxicity in Gyps vulture is associated with decreased uric acid excretion and not renal portal vasoconstriction. Comp. Biochem. Physiol. - C Toxicol. Pharmacol. 149: 269-274.

Naidoo, V. et al., 2011. The Pied Crow (Corvus albus) is insensitive to diclofenac at concentrations present in carrion. J. Wildl. Dis. 47: 936-944.

Naidoo, V. et al., 2017. Environ. Res.152: 150 156.

Oaks, J. L. et al., 2004. Diclofenac residues as the cause of vulture population decline in Pakistan. Nature427: 630-633.

Parker, J. M., et al., 1986. New hydrophilicity scale derived from high-performance liquid chromatography peptide retention data: correlation of predicted surface residues with antigenicity and X-rayderived accessible sites. Biochemistry 25: 5425-5432.

Pecora A, et al., 2009. Development and validation of an ELISA for quantitation of Bovine Viral Diarrhea Virus antigen in the critical stages of vaccine production. J. Virol. Methods. 162: 170-178
Prakash, V. et al., 2017. Recent changes in populations of Critically Endangered Gyps vultures in India. Bird Conserv. Int. 1-16.

Rattner, B. A. et al., 2008. Apparent tolerance of turkey vultures (Cathartes aura) to the non-steroidal anti-inflammatory drug diclofenac. Environ. Toxicol. Chem.27: 2341-2345.

Swan, G. E. et al., 2006. Toxicity of diclofenac to Gyps vultures. Biol. Lett.2: 279-282.

Swan, G. et al., 2006. Removing the threat of diclofenac to critically endangered Asian vultures. PLoS Biol.4: e66.

Swarup, D. et al., 2007. The safety of meloxicam to critically endangered Gyps vultures and other scavenging birds in India. Anim. Conser.10: 192-198.

Tam J.P. 1988. Synthetic peptide vaccine design: synthesis and properties of a highdensity multiple antigenic peptide system. Proc Natl Acad Sci. 85(15):5409-5413.

Towbin, H. et al., 1979. Electrophoretic transfer of proteins from polyacrylamide gels to nitrocellulose sheets: procedure and some applications. Proc. Natl. Acad. Sci. U. S. A.76: 4350-4354.

Van A et al., 2005. Human organic anion transporter MRP4 (ABCC4) is an efflux pump for the purine end metabolite urate with multiple allosteric substrate binding sites. Am. J. Physiol. Physiol.288: F327F333.

Zorrilla, I., et al., 2015. Suspected flunixin poisoning of a wild Eurasian Griffon Vulture from Spain. Conserv. Biol.29: 587-592.

\section{How to cite this article:}

Mashidur Rana, Mohini Saini, Sasmita Barik, Ram Bachan, Deepika Bisht, Supriya Bhattacharya, P. Kirthika, Praveen Singh, Satish Kumar and Praveen K. Gupta. 2018. Synthesis and Evaluation of Gyps vulture Multidrug Resistant Protein 4 (MRP4/ABCC4) Specific Multiple Antigenic Peptide (MAP) for its Immunoreactivity. Int.J.Curr.Microbiol.App.Sci. 7(12): 1656-1668. doi: https://doi.org/10.20546/ijcmas.2018.712.193 